Research Article

\title{
Study on the Valuation Method for Overseas Oil and Gas Extraction Based on the Modified Trinomial Tree Option Pricing Model
}

\author{
Jianye Liu $\mathbb{D}^{1},{ }^{1}$ Zuxin Li $\mathbb{D}^{1,2}$ Dongkun Luo ${ }^{1}{ }^{1}{ }^{1}$ and Ruolei Liu ${ }^{1}$ \\ ${ }^{1}$ School of Business Administration, China University of Petroleum (Beijing), 18 Fuxue Road, Changping District, \\ Beijing 102200, China \\ ${ }^{2}$ Institute of Petroleum Exploration and Development of China National Petroleum Corporation, Beijing 100083, China
}

Correspondence should be addressed to Jianye Liu; jianyeliu2015@163.com,Zuxin Li; leezx-69@hotmail.com, and Dongkun Luo; lizx609@163.com

Received 25 December 2019; Accepted 20 April 2020; Published 12 May 2020

Academic Editor: Jian G. Zhou

Copyright $\odot 2020$ Jianye Liu et al. This is an open access article distributed under the Creative Commons Attribution License, which permits unrestricted use, distribution, and reproduction in any medium, provided the original work is properly cited.

\begin{abstract}
Wandering of oil prices at lower values and the bitter reality have forced people to look for a more accurate valuation method for overseas oil and gas extraction of China. However, the currently available resource classification method, discount cash flow (DCF) method, and real option method all suffer from their own disadvantages. This paper identifies multiple uncertainty factors such as oil prices and reserves. It then investigates the transmission mechanism of how each uncertainty factor impacts the oil and gas extraction value and quantifies the transmission efficiency. The probability distribution patterns of each uncertainty factor have been determined; the trinomial tree option pricing model is modified, with consideration upon the nonstandardness of the probability distribution. Decision points and strategies space are designed in accordance with the practical oil and gas production; and the Bermuda option is adopted to replace the conventional decision-based tree model with the probability-based tree. Finally, a backward algorithm is developed to calculate the probability at each decision point, which avoids difficulties in determining the asset volatility ratio; and a case study is presented to demonstrate application of the proposed method. Results show that decision rights for overseas investment are valuable. The value of extraction does not yet necessarily grow with higher uncertainty, and instead, it is under joint effects of the cash flow and strategy space. So, valuation should incorporate the composite value of future cash flow and decision rights. Volatility of the value of extraction is not solely dependent on the oil price, but affected by multiple factors. Similar to the Bermuda option, the decision-making behavior for oil and gas extraction occurs only at finite decision points, to which the trinomial tree option pricing model is applicable. The adoption of probability distribution can to a great extent exploit the uncertain information. Replacement of the decision-based tree with the probability-based tree provides more accurate probability distribution of the calculated value of extraction, and moreover the disperse degree of the probability can reflect how high risks are, which is conducive to decision-making for investment.
\end{abstract}

\section{Introduction}

Since the 21th century, the foreign dependency of China's crude oil has been evergrowing, due to the increasing oil demand [1]. In this regard, major oil and gas companies in China all develop their overseas development strategies for "going out" [2,3]. After nearly 20 years of international development, oil and gas companies of China have possessed some oil and gas blocks in the central Asia, Africa, etc. However, these blocks are often seen with inferior opulence in resources and in many cases, they are located in high-risk countries [4].

In recent years, China has further increased its investment in overseas oil and gas assets, resulting in a significant increase in overseas oil and gas production. As shown in Figure 1, the overseas oil and gas production of China's three major oil companies, CNPC, SINOPEC, and CNOOC, increased by $90 \%, 41.6 \%$, and $177 \%$ in 2018 compared with 2011. 


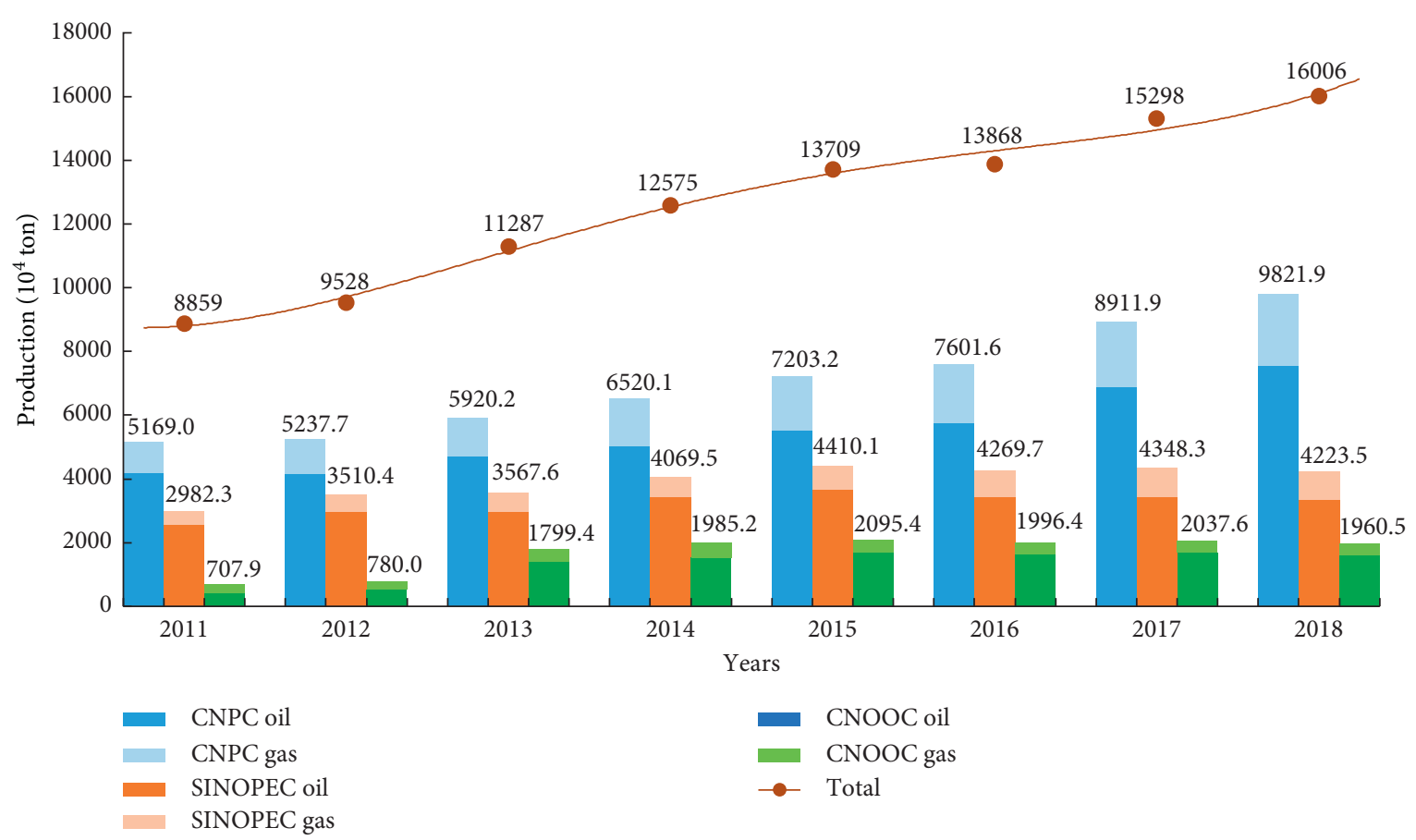

FIGURE 1: The overseas oil and gas production of CNPC, SINOPEC, and CNOOC $\left(1255 \mathrm{~m}^{3}\right.$ of natural gas production converted to 1 ton of crude oil production).

Hence, the investment evaluation for oil and gas extraction is of extreme importance. With the prolonged downturn of oil prices, there will be more opportunities to acquire overseas oil and gas assets; however, higher requirements are also raised up upon decision-making in acquisition and extraction. For oil and gas blocks that have been through deepened exploration and already put into development, valuation is relatively simple. The available elaborate geological and production data are sufficient to build the geological model and gas production forecast model, which are able to offer relatively precise valuation of assets [5]. Nonetheless, as for oil and gas blocks with unclear geological setting and incomplete data, the existing conventional method fails to accomplish asset valuation, due to its high uncertainty [6]. China's overseas oil and gas development business starts relatively late, and correspondingly, the current assets mostly belong to the latter case [4]. Accordingly, a valuation method specific to oil and gas extraction with higher uncertainty is required.

Based on the Modified Trinomial Tree Option Pricing Model, and considering the fluctuation of asset uncertainty, this research explores the value of decision rights at each decision point in overseas oil and gas asset evaluation and proposes an asset evaluation method. Firstly, this paper presents an overview of existing evaluation methods for overseas oil and gas assets and reveals that the existing methods have some defects in calculating the value of decision rights under uncertain conditions. Secondly, it identifies some uncertainty factors of overseas oil and gas assets, analyzes how these factors exert impacts on the asset value, and constructs a formula to estimate the cash flow of oil and gas asset development. Thirdly, it holds that there are five main decision points and three strategy types in the oil and gas investment process. By improving the trinomial tree option pricing model and combining with the distribution and types of uncertainty factors, this paper finally presents an evaluation method that is based on the probability tree of oil and gas exploration and development and that can be used to calculate the value of decision rights at each decision point in inverse order and the overall oil and gas asset value, and also it gives some examples to illustrate the application of this method.

\section{Literature Review}

The evaluation of oil and gas extraction refers to the economic benefit evaluation of the future exploration, development, and sales process of oil and gas assets. Besides the direct extraction value, the value of overseas oil and gas assets also includes strategic value, social value, and political value, which are not within the scope of this paper. In terms of valuation of oil and gas extraction with higher uncertainty, the current research approach can be divided into two groups: One is the quantitative analysis based on modelling and computing, including the discounted cash flow and real options valuation. The other is the qualitative or semiquantitative research based on decision-makers' perceptions, such as the Delphi method and resource classification method.

For the qualitative analysis, the Delphi method is susceptible to personal preferences and knowledge limitations of surveyed experts and has been discarded as the core valuation method for investment decision-makers. The resource classification method $[7,8]$ is a semiquantitative 
method for comprehensive valuation of oil and gas assets, involving grading hydrocarbon resources in accordance with reserve quantities, recovery difficulties, oil and gas quality, external risks, etc. This method is relatively accurate and moreover simple and can easily determine at which grade a certain oil and gas asset stays. However, comprehensive grading based on this method is somewhat subjective and has difficulties in deciding which has higher values, a block with a smaller scale and yet better quality, or the one with secondary quality but expanded reserve quantities? Under such circumstances, weights shall be assigned to each grading indicator by the decision makers, and therefore, this semiquantitative method is applicable to fuzzy comparison and preliminary screening out of multiple blocks.

Valuation of overseas oil and gas extraction demands more precise quantitative research to support investment decision-making, especially during the current downturn of oil prices. With respect to quantitative research, the mainstream method should be the discounted cash flow (DCF) method based on input and output. The DCF method [9] is widely used in the oil and gas industry and is able to present relatively high precision in the case of oil and gas blocks with lower certainty. Taking the time value of money into consideration, it precisely calculates the value of extraction by estimating the exploration and development investment, operation expenditure, and mortgages and taxes and predicting the sales revenue of crude.

Nevertheless, the estimation of investment, cost, and sales revenue in this method requires low uncertainty of the evaluated object; otherwise the calculated NPV (net present value) will not have credibility [10]. Moreover, the DCF method only considers the value of future cash flow and neglects the value of decision-making. Clearly, for overseas oil and gas extraction, the value of decision-making is embodied as the ability to give up exercising rights, which means stopping exploitation in the case of money-losing oil and gas investment [11]. This is a limitation of the DCF method.

Some scholars introduce the option method to deal with uncertainty of overseas oil and gas extraction, calculate the comprehensive value, and determine the investment timing. The real options method $[12,13]$, as an evaluation approach, estimates the financial value of oil and gas extraction through the DCF process, then calculates the option value using the volatility ratio of the asset value, and at last concludes the comprehensive value. The real option method is able to better mimic the decision-making behavior and measure the value of the decision right, by considering and calculating values of options to defer investment and to abandon.

Yet, some issues still exist in terms of the basic assumption and actual implementation and have not been well handled. Firstly, it is hard to measure the volatility ratio of the value of extraction. Transactions of oil and gas assets are characterized by their small quantity and discontinuation, and thus the value volatility ratio cannot be directly calculated. Generally, the real option method $[12,14,15]$ uses the oil price fluctuation to represent the undulation of the oil and gas asset value, between which the consistency has not been confirmed yet. In fact, the value of oil and gas assets is not only related to oil prices but also related to many other factors such as the level of risks associated with the resources, the local political and economic status, and laws. This is considered a major flaw of this method. Secondly, there is no complete market for oil and gas assets, like that for option transactions. The excessively limited quantity of buyers and sellers decides that the transaction is not realtime, and various options cannot be exercised in a timely fashion. Furthermore, the transaction value of assets is largely determined through the game between the two sides and the transaction value of options is hard to be estimated. In addition, some studies [16] reject two stylized facts of real options on oil: one is that the correlation of the returns on oil and the stock market is positive; the other is that it is invariant to changes in oil price volatility. They state that the widespread idea that higher volatility leads to increased value and postponed investment is not necessarily valid.

To sum up, regarding valuation of overseas oil and gas extraction, the qualitative method suffers from insufficient precision, the DCF method fails to capture the value of decision rights, and the basic assumption of the real option method is questionable. Therefore, it is required to think about it further to overcome these defects.

\section{Analyzing Uncertainties of Overseas Oil and Gas Extraction}

The value of the decision rights for overseas oil and assets roots in uncertainty, and thus we should first clarify in which aspects uncertainty is embodied, then analyze how these uncertain factors impact the assessed value of assets, and at last characterize variations of these uncertainty factors.

3.1. Identification of Uncertainty Factors. Overseas oil and gas extraction are subject to various uncertainty factors, of which extensive identification investigation and subsequent risk quantification and asset valuation have been carried out. Most scholars [17-20] focus on uncertainty in the geology, which mainly include the reserves, quality, depth, utilization rate, production rate, and decline rate of production. Some scholars $[21,22]$ also consider the external environment, including the political and economic environment, sovereignty credit, and global oil price. Besides, the geographic location, topographical setting, hydrogeological background, and technical proficiency of operators, which are concerned with the discovery, development, construction, and operating costs during hydrocarbon recovery, also have effects upon the value of assets. In summary, the uncertainty factors can be classified into the following categories, as shown in Table 1.

Geological factors of resources refer to the geological conditions of oil and gas resources, and their uncertainty is mainly caused by the error of measurement results of exploration experimental wells. These uncertainty factors are mostly derived from the low level of exploration and fuzziness in geological data and will gradually decline with the progressing geological understanding. The uncertainty factors of production parameters mainly refer to the 
TABLE 1: Uncertainty factors of overseas oil and gas extraction.

\begin{tabular}{lr}
\hline Categories & Uncertainty factors \\
\hline Resource geology & Oil and gas resource quantity, quality, depth \\
Production parameters & Rate of utilization, production, decline \\
External environment & Politics, economics, sovereignty credit, global oil price \\
Others & Geography, topography, hydrology, operational proficiency \\
\hline
\end{tabular}

parameters in the production process, which are influenced by the geological conditions, technical level of producers, and the preference of decision makers, and have certain subjectivity. External environmental factors mainly refer to the political and economic environment of the target area, which are objective macrofactors. Other factors, however, due to the relatively low level of uncertainty, are not considered in this research.

3.2. Uncertainty Transmission. Uncertainty of each factor is ultimately transmitted onto the extraction value, which is embodied as the uncertainty of the value of overseas oil and gas extraction. The transmission mechanism of uncertainty factors is illustrated in Figure 2.

The reserves, utilization rate, production rate, and decline rate impact the ultimately recovered saleable resources, The larger the reserves, the higher the utilization ratio, the faster the production rate, the slower the decline rate, then, the larger the saleable resources. However, the increase of production rate will also generally lead to the increase of decline rate. The production rate and decline rate together affect the production curve of the whole life cycle, which further results in influence upon the time value of capital. Even if it has the same total production, the net present value of different production curves is different. It is obvious that earlier recovery of hydrocarbons is favorable to amortizing the capital and repaying the loan. The resource quality and the global oil price have effects upon the final sales price, and heavy oil and light oil are seen with different global prices. Generally, quality compensation is used to represent the quality of resources. The worse the resource quality is, the higher the amount of compensation is needed, and the lower the value of extraction is. Furthermore, the burial depth of resources is one of the decisive factors for drilling cost. Higher capitalized costs compromise the value of extraction.

The above work clarifies the route of each uncertainty factor to influence the value of oil and gas extraction, and yet how much the influence is cannot be calculated through the presented figure. Thus, we need to further investigate the efficiency of such a transmission mechanism. The value of oil and gas extraction is dependent on the cash flow generated by future oil and gas production, and the cash flow component is shown in Figure 3.

The roles played by uncertainty factors in terms of cash flow generation are illustrated in Figure 3. For cash outflow, the amount of the predicted resources is related to the exploration area, which will determine the exploration investment, and reserves discovery cost is generally used to quantify the investment. The initial annual production will affect the facilities construction investment, and the total output will affect various CAPEXs (capital expenditure) and OPEXs (operating expense) and then indirectly affect the expenditure of taxes; of course, all expenditures are influenced by the investment environment, tax laws, and local communities, such as the level of local prices, which will affect the workers' wage. For cash inflows, global oil prices and the resource quality will affect sales prices, while production and sales prices determine the sales revenue. Efforts could be made to formulize these routes of cash flow generation, which is in accordance with financial appraisal of oil and gas production.

Many studies on oil and gas investment appraisal $[19,23]$ have discussed those formulas, and here a complete formulized description of cash inflow and outflow for oil and gas development is presented.

In terms of exploration investment, it is related to predicted recoverable reserves, and also the discovery cost per barrel oil. Therefore, it can be expressed as

$$
I_{\text {exp }}=I_{\text {exp } / \mathrm{bbl}} \times R_{\text {rec }} R_{\text {rec }}=R_{\text {pre }} \times r_{\text {rec }} r_{\text {rec }}=\sum_{t=1}^{n} r_{\text {pro }}\left(1-r_{\text {del }}\right)^{t-1}
$$

where $I_{\exp }$ is the exploration investment; $I_{\exp / \mathrm{bbl}}$ is the discovery cost per barrel oil; $R_{\text {rec }}$ are the predicted recoverable reserves; $R_{\text {pre }}$ are the predicted development pending resources; $r_{\text {rec }}$ is the recovery factor; $r_{\text {pro }}$ stands for the production rate; $r_{\text {del }}$ represents the decline rate; $n$ is the estimated recovery lifecycle.

As for development investment, it is primarily dependent on the predicted reserves, and utilization and production rates, and can be calculated as follows:

$$
\begin{aligned}
I_{\mathrm{dev}} & =I_{\mathrm{dev} / \mathrm{bbl}} \times P_{\text {total }}, \\
P_{\text {total }} & =R_{\text {pre }} \times r_{\text {uti }} \times r_{\text {rec }},
\end{aligned}
$$

where $I_{\mathrm{dev}}$ is the development investment, including investment on drilling, fracturing, and completion; $I_{\mathrm{dev} / \mathrm{bbl}}$ is the development investment per barrel oil; $P_{\text {total }}$ is the total production; $r_{\text {uti }}$ is the utilization rate.

Then, for construction investment, it mainly involves construction of surface oil and gas processing facilities, which is correlated to the maximum annual hydrocarbon output, instead of total production. Higher annual production results in higher construction investment, which can be computed using the following equation:

$$
\begin{aligned}
& I_{\text {con }}=I_{\text {con } / \mathrm{bbl}} \times P_{\text {ini }}, \\
& P_{\text {ini }}=R_{\text {pre }} \times r_{\text {uti }} \times r_{\text {pro }},
\end{aligned}
$$

where $I_{\text {con }}$ is the construction investment; $I_{\text {con/bbl }}$ is the construction investment per barrel oil; $P_{\text {ini }}$ stands for the initial annual production. 


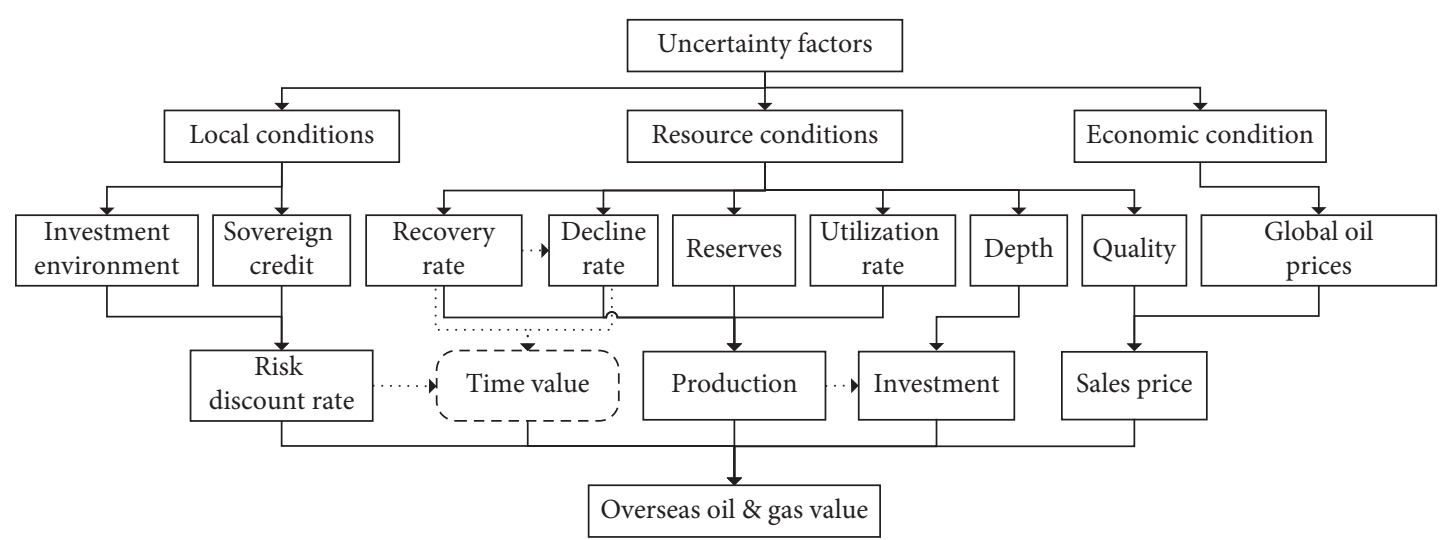

FIGURE 2: Transmission of uncertainty with respect to the value of overseas oil and gas extraction.

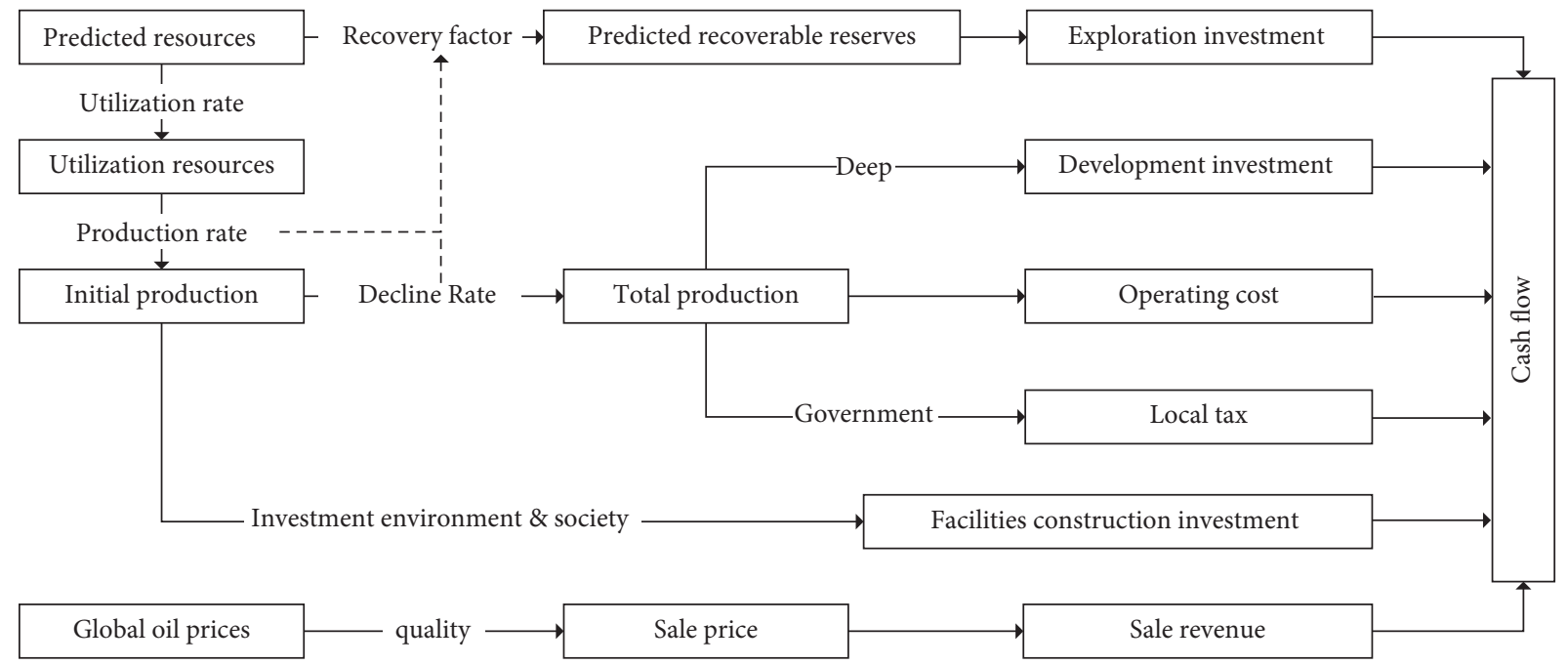

Figure 3: Components of the future cash flow of overseas oil and gas extraction.

The sales revenue is determined by the global oil price, quality of produced oil and gas, and produced amount of oil and gas. Calculation can be done using the following equation:

$$
\begin{aligned}
R_{\text {sal }} & =P_{\text {s-price }} \times P_{\text {total }}, \\
P_{\text {s-price }} & =P_{\text {g-price }}+i_{\text {qua }},
\end{aligned}
$$

where $R_{\text {sal }}$ is the sales revenue; $P_{\text {s-price }}$ is the sale price; $P_{\text {g-price }}$ is the global oil price; $i_{\text {qua }}$ is the price variation dependent on quality of hydrocarbon resources, which may be negative.

Calculating the operating cost and tax is relatively simple and can be shown via the following equation:

$$
\begin{aligned}
T_{\text {tax }} & =T_{\text {tax } / \mathrm{bbl}} \times P_{\text {total }}, \\
C_{\text {opex }} & =C_{\text {opex } / \mathrm{bbl}} \times P_{\text {total }},
\end{aligned}
$$

where $T_{\operatorname{tax}}$ stands for taxes; $C_{\text {opex }}$ is the operating cost; $T_{\operatorname{tax} / \mathrm{bbl}}$ is the average tax per barrel oil; $C_{\text {opex/bbl }}$ is the operating cost per barrel oil.

To sum up, the composition of future cash flow of oil and gas assets development is shown in Table 2:

3.3. Distribution Patterns of Uncertainty Factors. Having formulized the path of influence of each uncertainty factor
TABle 2: Cash inflow and outflow of oil and gas assets.

\begin{tabular}{lccc}
\hline Categories & Cash flows & Notation & Workflow stage \\
\hline & Exploration investment & $I_{\exp }$ & Exploration \\
& Development & $I_{\mathrm{dev}}$ & Development \\
Outflow & investment & $I_{\text {con }}$ & Development \\
& Construction investment & $C_{\text {opex }}$ & Sale \\
& Operating cost & $T_{\text {tax }}$ & Sale \\
\hline Inflow & Taxes & $R_{\text {sal }}$ & Sale \\
\hline
\end{tabular}

for future case flow of oil and gas extraction and clarified the transmission mechanism of the uncertainty factor for the value of extraction, we are still facing undefined degrees of uncertainty for each factor itself. In other words, investigation of the distribution pattern of each factor should be carried out, e.g., volatility of oil prices.

In reference to volatility of each uncertainty factor, many factors have available literatures for references. Regarding reserves, extensive research in the petroleum engineering industry $[24,25]$ suggests that the oil reserve is undoubtedly found with the logarithmic normal distribution, instead of the normal distribution assumed by some researchers in the 
real option field. For the distribution of oil prices, an agreement in understanding among extensive scholars has not been reached yet. Some $[15,26]$ believe that oil price variation should be a type of geometric Brownian motion, while others [20, 27-30] conduct oil price forecast using the support vector machine, Bayesian model, system simulation, or a combination of multiple approaches, with various corresponding results. This paper tends to believe that oil price complies with the Mean-Reversion with Jumps [26], which means that oil price is endowed with a mean-reversion nature, and the mean oil price will gradually grow with time, in case of no unexpected outburst events.

In terms of quality and depth of resources, both are determined according to the results of exploration experimental Wells. The uncertainty of resource depth comes from the measurement error of experimental well depth, and the uncertainty of resource quality comes from the measurement error of sulfur content and other indicators. Therefore, they can be considered as normal distribution and can be expressed by quality compensation amount and drilling cost.

Utilization rate, production rate, decline rate, and other factors are to some extent subject to the subjective influence of the developer; after consulting relevant experts, we make the following assumptions: For the utilization rate, it should be within $[0,1]$, and we assume that it obeys the trapezoidal distribution, having probability within a certain subinterval much higher than the average. The production rate of resources is somewhat susceptible to subjectivity and, meanwhile, is also constrained by geological conditions. It should be within $(0,1)$, with the existence of an optimal value, and is therefore assumed to follow the triangular distribution. The decline rate of hydrocarbon recovery, with a supposed range of $(0,1)$, is related to the production rate and also under the constraints of geological conditions. Consequently, it is also assumed to follow the triangular distribution. When it comes to the discount rate of risks, it is dependent on the local investment and financing environment, sovereignty credit, and politics. Its distribution pattern is still unclear. For projects with low risks, it may present the T-shaped distribution, while for projects with higher risks, it may follow the normal distribution, and we have not reached an agreement yet. In addition, in most cases, the risk-free rate of return is replaced with the long-term treasury bond rate (LTBR) of the US, and the risk-free rate plus the risk discount rate should be the discount rate $i$ used in calculating net present values.

To sum up, the distribution patterns of uncertainty factors are summarized in Table 3:

\section{A Modified Approach Based on the Trinomial Tree Option Pricing Model}

Upon accomplishment of identification of uncertainty factors and investigation of transmission routes and distribution patterns of probability, we are able to calculate the net present value distribution, on the basis of the established probability density function and transmission route formula of uncertainty factors. The calculation is simple, as is shown in equation (6), and the expectation value and variance of net present values can be obtained, which is similar to the appraisal concept based on the DCF method. Nonetheless, such practice still neglects the value of decision rights, and thus, we need to modify the trinomial tree option pricing model in a way inspired by the real options method:

$$
\begin{aligned}
\mathrm{NPV}= & \sum_{t=1}^{n}\left(R_{\text {sal }-\mathrm{t}}-I_{\text {exp- } \mathrm{t}}-I_{\text {dev }-\mathrm{t}}-I_{\text {con }-\mathrm{t}}-C_{\text {opex }-\mathrm{t}}-T_{\text {tax }-\mathrm{t}}\right) \\
& \times(1+i)^{-t},
\end{aligned}
$$

where NPV is the net present value of overseas oil and gas extraction; $i$ is the discount rate; $R_{\text {sal- } t}, I_{\text {exp-t }}, I_{\text {dev-t }}, I_{\text {con- } t}, C_{\text {opex-t }}$ and $T_{\text {tax-t }}$ are the sales revenue, exploration investment, development investment, construction investment, operating cost, and taxes at the $t$-th year, respectively (in case of no income or expense under a specific term, it should be zero).

\subsection{Decision Points and Strategies during Appraisal (Deferred} Development, Immediate Development, and Sale of Assets). The real option method can deal with the asset volatility ratio via an approach combing the uncertainty factor and the transmission route formula, since the calculated net present value presents itself as a distribution. It should be noted that the resultant distribution does not necessarily follow the normal or logarithmic normal distribution, and therefore some currently available option calculation models may be inapplicable. The volatility ratio of the calculated distribution does not solely depend on the oil price; this single uncertainty factor, instead, should be computed using multiple factors through the transmission route formulas.

Another major disadvantage of the real option method is that exercising rights cannot be done in a real-time manner. It is not like that one can immediately exercise the right at any moment, and there is no such thing as a simple switch for turning on and off lights to allow for immediate startup, suspension, and termination of petroleum exploration and development. For example, the option to defer cannot be exercised in the middle of drilling to instantaneously shut down the development. Oil and gas fields cannot be sold out during exploration and development to exercise the option to abandon. Consequently, the timing at which it is feasible to exercise the option should be analyzed, which is referred to as the decision point in this paper. At non-decision points, options cannot be exercised or partially exercised to defer or abandon.

The general extraction workflow of oil and gas is illustrated in Figure 4. At each decision point occurs a decisionmaking behavior, which may have various strategy spaces. The corresponding decision space is concluded in Table 4.

Here is a brief statement of the strategy space of each decision point listed in Table 4. For each major stage, we have three strategies, namely, starting investment, deferring and waiting, and abandoning investment, right before initiation of exploration, development, and sale. In this regard, this paper is consistent with Tang et al. [13]; yet two additional intermediate decision points are considered in this paper. After accomplishment of regional exploration, a preliminary appraisal is carried out before trap exploration, which is consistent with the practice of oil companies. If regional exploration presents favorable results, exploration 
TABLE 3: Distribution patterns of uncertainty factors for overseas oil and gas extraction.

\begin{tabular}{lcccc}
\hline Uncertainty factor & Distribution pattern & Source & Range & Additional remarks \\
\hline Resource reserves & Logarithmic normal distribution & Reliable literature & $>0$ & - \\
Sale price of oil & Mean-reversion with jumps & Available literature & $>0$ & Mean value growing with time \\
Resource depth & Normal distribution & - & $>0$ & The measurement error is normally distributed \\
\hline Resource quality & Normal distribution & - & - & \\
Utilization rate & Trapezoidal distribution & Assumed & {$[0,1]$} & Consulting relevant experts\& consider the reality \\
Rate of production & Triangular distribution & Assumed & $(0,1)$ & \\
Decline rate & Triangular distribution & Assumed & $(0,1)$ & Not in an agreement \\
\hline Discount rate & T-shaped or normal distribution & Assumed & - & \\
\hline
\end{tabular}

$\underbrace{\underbrace{\text { Trap exploration }}_{\text {Regional exploration }}}_{\text {Exploration }} \underbrace{\text { Drilling engineering }}_{\text {Development }}$

FIGURE 4: Workflow of overseas oil and gas exploration and development.

TABLE 4: Decision points and their strategy space for overseas oil and gas extraction.

\begin{tabular}{lcc}
\hline Stage & Decision point & Strategy space \\
\hline Exploration & $\begin{array}{c}\text { Before regional } \\
\text { exploration } \\
\text { Before trap exploration }\end{array}$ & $\begin{array}{c}\text { Begin, defer, abandon } \\
\text { Continue, abandon }\end{array}$ \\
\hline Sale & Before drilling & $\begin{array}{c}\text { Continue, defer, } \\
\text { abandon } \\
\text { Continue, defer }\end{array}$ \\
\hline
\end{tabular}

goes on; otherwise, it will be abandoned. Moreover, after finishing the drilling engineering, some oil and gas companies may decide not to perforate the payzone for the time being and wait for the right moment, in accordance of their own status and estimation of future oil price and supply tendencies. It is based on this very fact that the decision point is designed.

In addition to the five main decision points mentioned above, in fact, there are many possible accidental decision points in the process of oil and gas extraction. For example, large fluctuations of the oil price may delay or bring forward the exploration, safety incidents may lead to the suspension of some Wells, and oil and gas production may be suspended for political reasons. However, it is difficult to predict whether these decision points will occur, when they will occur, and how long a project may be suspended. Since this paper is only a method study, there is no obvious difference in the application of the method whether it is 5, 6, or more decision points; this model simplifies the actual situation and only considers 5 main decision points that inevitably exist.

\subsection{Modification to the Trinomial Tree Option Pricing Model.} On the basis of the analysis on the decision-making workflow presented above, it is found that investment on overseas oil and gas extraction is characterized by limited decision points and should be a type of Bermudan options, to which the tree option model is applicable, instead of the American-style or European-style options.

The conventional binomial modal develops the decisionmaking tree with respect to the probabilities of upward and downward movements. Magnitudes of upward and downward movements are dependent on the volatility ratio of the total asset. Therefore, there are infinite decision points, and the resultant ultimate value of extraction follows the probability distribution. However, decision points for overseas oil and gas extraction are finite, which means that one is incapable of simulating the asset volatility through infinite decision points. Moreover, the NPV at each decision point calculated using Table 3 and equations (1)-(6) presents itself as a distribution. Under such circumstances, we are not able to plot and handle an $\mathrm{N}$-ary tree with infinite upward and downward points. Given this, some modification has to be made upon the tree option pricing model. The tree is not plotted in accordance with upward and downward movements; instead, it is developed in reference to the strategy space. Consequently, we are able to calculate the probability distribution of the pre-decision value of extraction in a backward manner, as is shown in Figure 5.

The probability tree-based method to estimate value still adopts the concept of calculating the initial value of extraction in a backward manner, although it is slightly different with that based on the decision-making tree. First, the value at the last decision point, "before production," is computed. Upon accomplishment of exploration and development, there are three available strategies, namely, abandonment, deferring, and immediate production. In the case of the value at production higher than zero, decision makers will choose immediate development; in the case of the value at production lower than zero, decision makers will choose to abandon development and recover residual values, or straightforward sale of assets; with a production value of about zero, decision makes will choose to defer development and wait for growing back of oil prices. The specific bound limit is dependent on preferences for utilities of investors. 


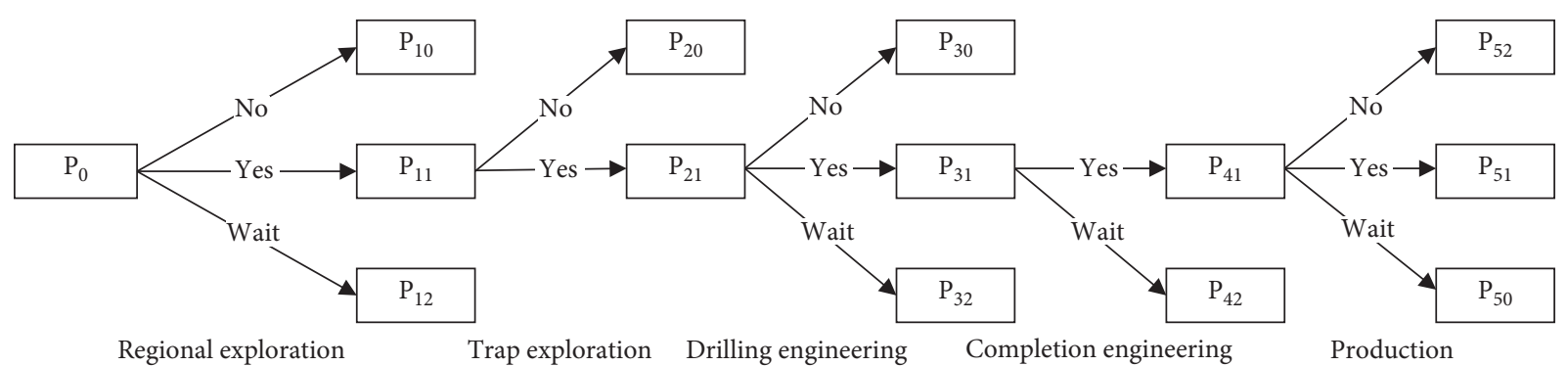

FIgURE 5: Probability tree of overseas oil and gas extraction (there are three possibilities of whether to proceed to the next stage: Yes means immediate development, No means immediate abandonment, and Wait means waiting for opportunity).

The value at this decision point can be expressed using the following equation:

$$
C_{5}= \begin{cases}V_{5}-I_{5}, & V_{5}>0, V_{5}=\sum_{t=t_{5}}^{n}\left(R_{\mathrm{sal}-t}-C_{\mathrm{opex}-t}-T_{\mathrm{tax}-t}\right) \times(1+i)^{-t}, \\ 0, & V_{5} \approx 0, \\ R_{\mathrm{rec}-5}-I_{5}, & V_{5}<0, I_{5}=\sum_{t=t_{4}}^{t_{5}}\left(I_{\mathrm{dev}_{2}-t}+I_{\mathrm{con}_{2}-t}\right) \times(1+i)^{-t},\end{cases}
$$

where $V_{5}$ is the present value of future earnings in case the oil and gas field is being developed; $I_{5}$ stands for the present value of investment made in the previous stage, which will become the sunk cost if the development is abandoned and the holding asset if the development is deferred; $t_{5}$ is the time corresponding to the decision point "before production"; $C_{5}$ is the value at the decision point; $R_{\text {rec }-5}$ refers to the residual value of previous investment that can be recovered if the development is abandoned or the value that the asset can realize in case it is sold out, generally far less than $I_{5}$. It should be noted that $V_{5}$ and $I_{5}$ calculated in accordance with Table 3 are probability distributions, instead of specific numbers.

Similarly, value distributions at other decision points can be computed, as is shown in the following equation:

$$
\begin{aligned}
& C_{1}= \begin{cases}C_{2}, & C_{2}>0, \\
0, & C_{2} \approx 0, \\
R_{\text {rec }-1}-I_{1}, & C_{2}<0,\end{cases} \\
& C_{2}= \begin{cases}C_{3}-I_{2}, & C_{3}>0, \\
R_{\text {rec }-2}-I_{2}, & C_{3} \leq 0,\end{cases} \\
& C_{3}= \begin{cases}C_{4}-I_{3}, & C_{4}>0, \\
0, & C_{4} \approx 0, \\
R_{\text {rec }-3}-I_{3}, & C_{4}<0,\end{cases} \\
& C_{4}= \begin{cases}C_{5}-I_{4}, & C_{5}>0, \\
0, & C_{5} \leq 0,\end{cases} \\
& I_{2}=\sum_{t=1}^{t_{1}}\left(I_{\exp _{1}-t}\right) \times(1+i)^{-t},
\end{aligned}
$$

where $I_{1}, I_{2}, I_{3}$ and $I_{4}$ are present values of existing investment at each decision point, respectively; $R_{\text {rec-1 }}, R_{\text {rec }-2}$ and $R_{\text {rec-3 }}$ are the investment residual values that can be paid back if the development is abandoned. In most cases, one will not abandon completion after finishing drilling, and the decision is limited to either immediate or deferred completion.

After obtaining distributions of the value at each decision point through backward calculation based on the probability tree, we can further compute the expected economic value with respect to the value distribution. For instance, at the first decision point, that is, before decisionmaking upon regional exploration, the incurred cost is the acquisition cost of the oil and gas asset $I_{1}$. If the development is implemented, the obtained revenue is $C_{2}$. In the case of deferred development, the investment changes into the asset, of which the value is assumed to be equal to the acquisition cost. Under the circumstance that the development is abandoned, part of previous investment will be lost. Given the aforementioned information, the expected value at the "before regional exploration" decision point is shown in the following equation:

$$
\begin{aligned}
E\left(C_{1}\right) & =\int_{0}^{P_{10}} R_{r e c-1}-I_{1}+\int_{P_{10}}^{P_{10}+P_{12}} 0+\int_{P_{10}+P_{12}}^{1} C_{2}, \\
P_{10} & =P\left(C_{2}<0\right) \\
P_{12} & =P\left(C_{2} \approx 0\right) \\
P_{11} & =P\left(C_{2}>0\right) .
\end{aligned}
$$

The expectation of the value of extraction at other intermediate decision points can be calculated in a similar approach, and thus detailed description is discarded here. 
4.3. Application of the Modified Method. In this paper, the conventional decision-based binomial model is replaced by the probability-based one. For purposes of understanding how this model can be applied, this paper takes an overseas oil and gas extraction project as an example to briefly demonstrate the application of the modified method.

Sudan $\mathrm{X}$ is an oil and gas block located in Africa that CNPC plans to invest in. This block is seen with no elaborate geological data, and only part of parameters required for asset appraisal can be determined, on the basis of analogous blocks. Acquisition of the exploration and development interest of this block costs three million USD, and the discovery cost per barrel oil $\mathrm{I}_{\text {exp/bbl }}$ is $1.2 \$ / \mathrm{bbl}$. The construction investment per barrel oil is $50 \$ / \mathrm{bbl}$, while the operating cost per barrel oil is $17 \$ / \mathrm{bbl}$. The composite tax rate is about $20 \%$. The estimated period of exploration lasts for two years, and production capacity construction needs three years, followed by a sustained recovery of 17 years. Other factors are all uncertain, with dispersed probability distribution and high uncertainty (Table 5).

It is easy to compute the probability distribution of annual production of each year, on the basis of the distributions of the resource reserves, utilization rate, production rate, and decline rate, equation (1) and the assumption that production capacity establishment can be completely finished within three years. The calculation process is illustrated in Figure 6.

With respect to oil price volatility, discount rate, and distribution of sale price variation induced resource quality, we can compute the distribution of the present value of earnings $V_{5}$ at each future year using equation (7). Results are presented in Figure 7.

It is seen that $V_{5}>0$ is highly likely, and thus at the decision point "production", strategies of deferring or abandoning are seldom chosen. This is consistent with our common observation. Once all investments of exploration and development are down, oil and gas operators barely decide to abandon production.

With equations (1)-(3) and distributions of relevant parameters, the probability distributions of $\mathrm{I}_{4}$ and $\mathrm{I}_{5}$ can be computed, which subsequently leads to the distributions of $C_{4}$ and $C_{5}$.

Figures 7 and 8 indicate high odds of the case of $C_{4}>0$ and $C_{5}>0$. This means that once oil and gas resources are found during exploration; probability of the proceeding development is very high. Given this, the values of the latter two decision points are overridden, which is inconsistent with the view held in the conventional real option law that higher uncertainty results in the higher asset value.

Similarly, the probability distribution of $C_{3}$ can be determined with the help of $I_{3}$ and $C_{4}$ and is shown in Figure 9.

Unlike other decision points, the future value at the decision point "trap exploration" presents negative values, which is decisive in whether or not to execute trap
TABle 5: Distribution of uncertainty factors in Block Sudan X.

\begin{tabular}{lc}
\hline Uncertainty factor & Distribution of affected parameters \\
\hline Resource reserves & $\operatorname{Ln}\left(R_{\text {pre }}\right) \sim N\left(9,0.42^{2}\right)$ \\
Global oil price & dLn $P_{\text {s-price }}=0.8\left(4-\operatorname{Ln} \mathrm{P}_{\text {s-price }}\right) \mathrm{dt}+0.02 \mathrm{~d} z_{t}$, \\
& $\mathrm{d} z_{t} \sim(0, \mathrm{~d} t)$ \\
Resource depth & $I_{\mathrm{dev} / \mathrm{bbl}} \sim \mathrm{N}\left(16,3.2^{2}\right)$ \\
Resource quality & $i_{\text {qua }} \sim \mathrm{N}\left(4,0.78^{2}\right)$ \\
Utilization rate & $r_{\text {uti }} \sim T_{\text {ra }}(0.8,0.85,0.94,1)$ \\
Production rate & $r_{\text {pro }} \sim T_{\text {ri }}(0.01,0.02,0.03)$ \\
Decline rate & $R_{\text {del }} \sim T_{\text {ri }}(0.15,0.2,0.22)$ \\
Discount rate & $i \sim 0.01 T(4)+0.1$ \\
\hline
\end{tabular}

${ }^{2}$ There are three possibilities of whether to proceed to the next stage: Yes means immediate development, No means immediate abandonment, and Wait means waiting for opportunity. ${ }^{3} \mathrm{Ps}$-price is the sales price of crude oil, Ln Ps-price refers to the logarithm of crude oil price, and 4 is the mean value of the logarithm of Brent oil price during 1999-2019; 0.8 is the reversion speed of the mean value; the larger the value is, the faster the logarithm of price approaches the long-term mean value; 0.02 is the logarithm volatility obtained by calculating the logarithms of Brent oil price in recent 20 years; $\mathrm{d} z_{t}$ refers to the standard Brownian motion, $\mathrm{d} z_{t} \sim(0, \mathrm{~d} t) .{ }^{4}$ The design of discount rate distribution is based on the discount rate currently used by CNPC, data from Evaluation parameters of investment projects of CNPC (2019).

exploration. If the future cash value is below zero, it is certain that investment stops. A recovery ratio of $20 \%$ is set for the total previous investment residual value, that is, $R_{\text {rec }-2}=20 \% I$. A range of $\left[-20 \% I_{2},+20 \% I_{2}\right]$ for $C_{3}$ is also set to define the case in which cash value is about zero. This range is man-made and, in fact, will not be used, given equation (8), since no deferring strategy exists at the trap exploration decision point. At last, the probability distribution of $C_{2}$ can be computed, on the basis of $I_{2}$ and $C_{3}$ (Figure 10).

From Figure 10, it is seen that the probability of $C_{2}$ below zero is significantly reduced, with decision-making before trap exploration. However, negative values still exist, because loss can be induced by volatility of uncertainty factors, even though rational decision-making has been executed. The decision-making behavior is able to only reduce such losses, and yet it is incapable of entirely avoiding such losses. Finally, the probability distribution of $C_{1}$ can be computed using equation (8), as is shown in Figure 11.

Figure 11 demonstrates that, before initiation of regional exploration, thanks to the availability of a waiting strategy, the calculated value distribution presents high probability for the value of about zero. The resultant expectation value of $C_{1}$ is 11.48 million USD.

In the case of the DCF method with no consideration of decision rights, the probability distribution of $\mathrm{C}_{1}$ calculated directly using equation (6) is plotted in Figure 12. The expectation value of C1-DCF calculated in this way is 10.58 million USD. 

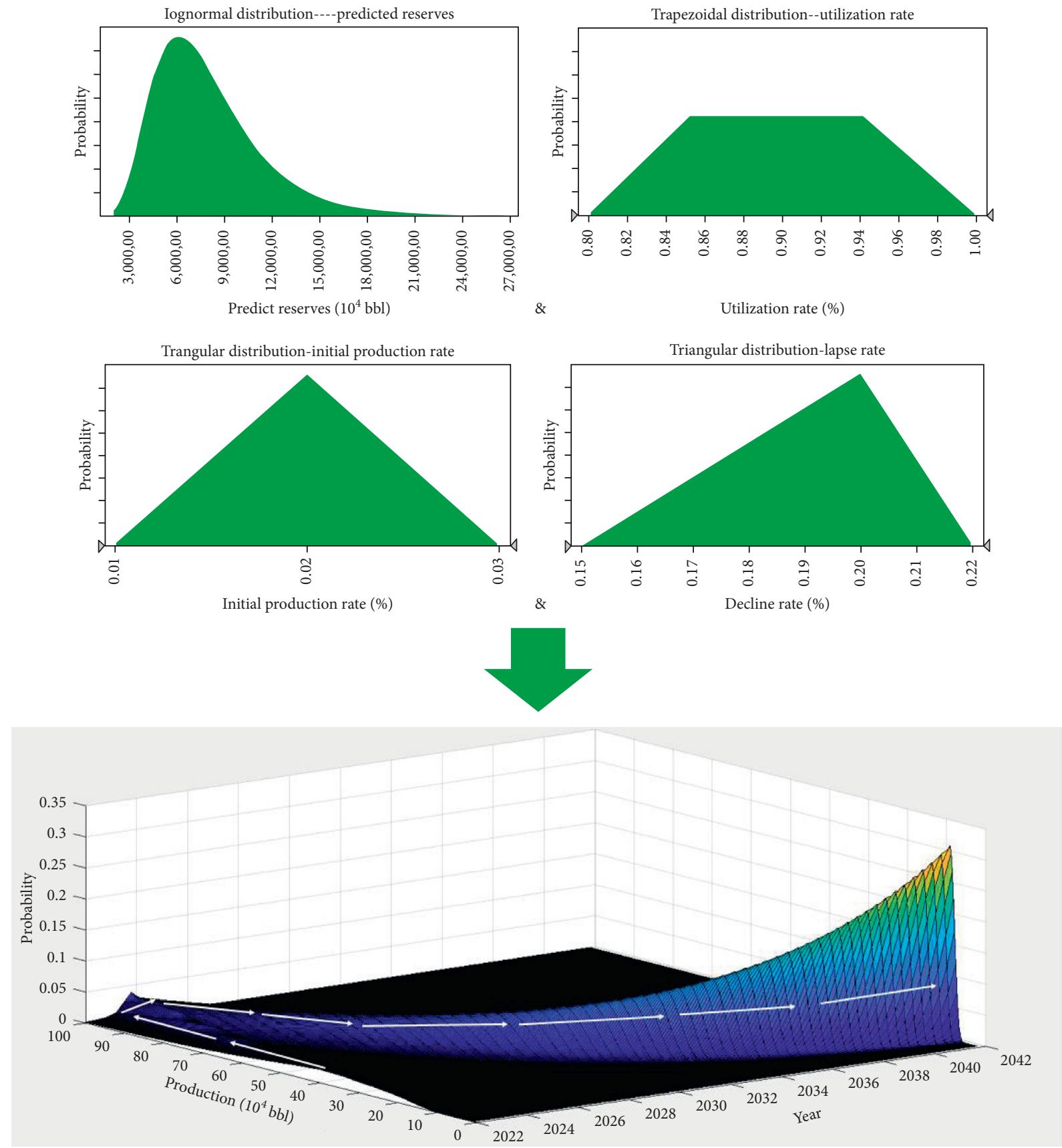

FIGURE 6: Probability distributions of predicted reserves, utilization rate, production rate, decline rate, and annual production of each year.

We have calculated the oil and gas asset value at each decision point without options and made a comparison between the oil and gas asset value at the decision point with and without options. The comparison results are shown in Table 6

Therefore, it is safe to say that, for Block Sudan X, decision rights at each decision point do possess values, which are about 0.9 million USD in total. For Block Sudan X, decision rights at decision points $C_{1}, C_{2}$ and $C_{3}$ do possess practical values, and it does not seem that the value of decision rights at the latter two decision points would have great increase due to continuous development. Furthermore, the disperse degree of the value probability distribution can represent the degrees of the aggregate risk of the investment. Figures 11 and 12 present varied disperse degrees, in terms of the distribution. Figure 11 is observed to be more concentrated in the portion above zero, which suggests reasonable future decisions can reduce risks. 


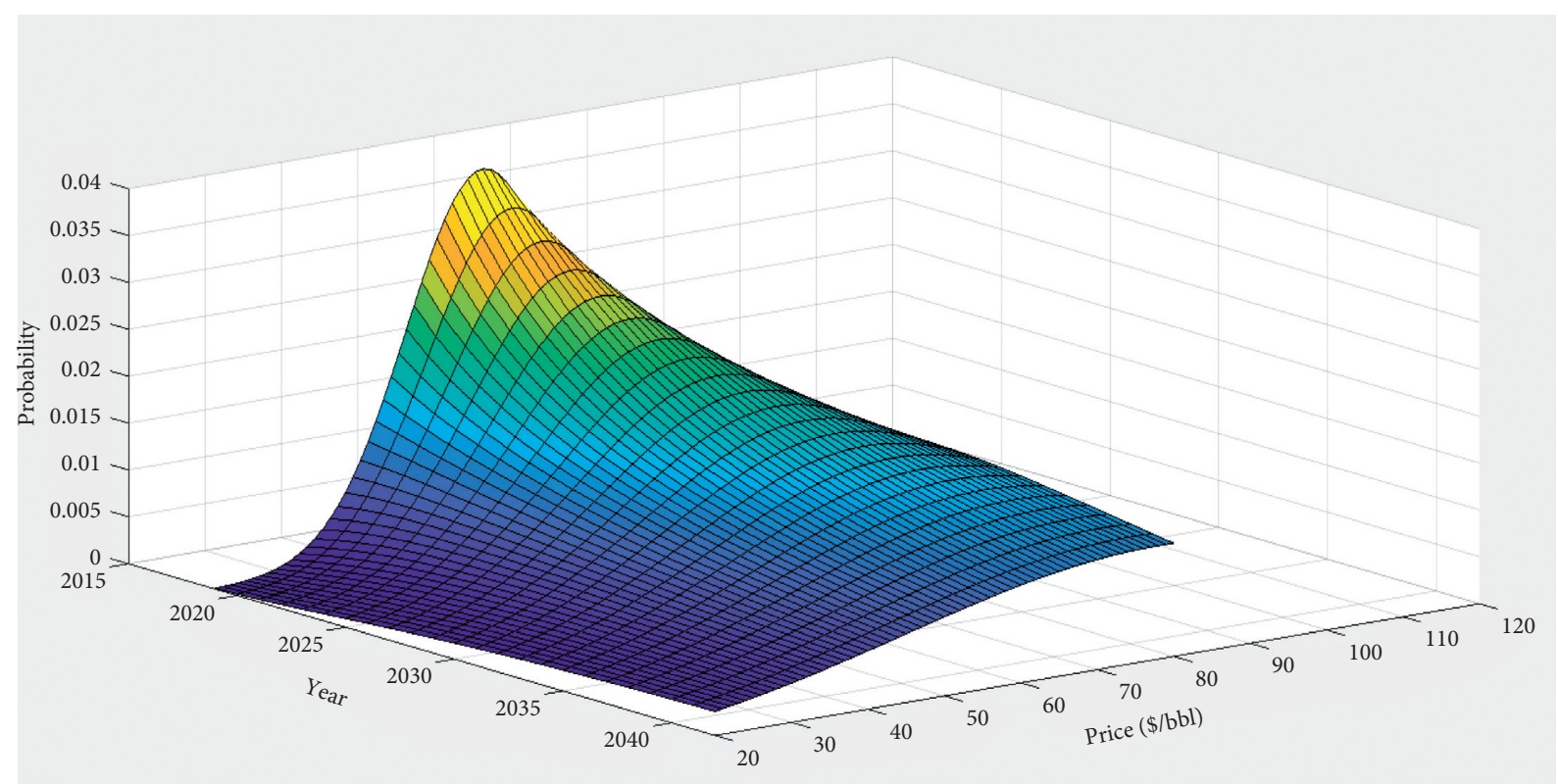

Global oil price (\$/bbl)
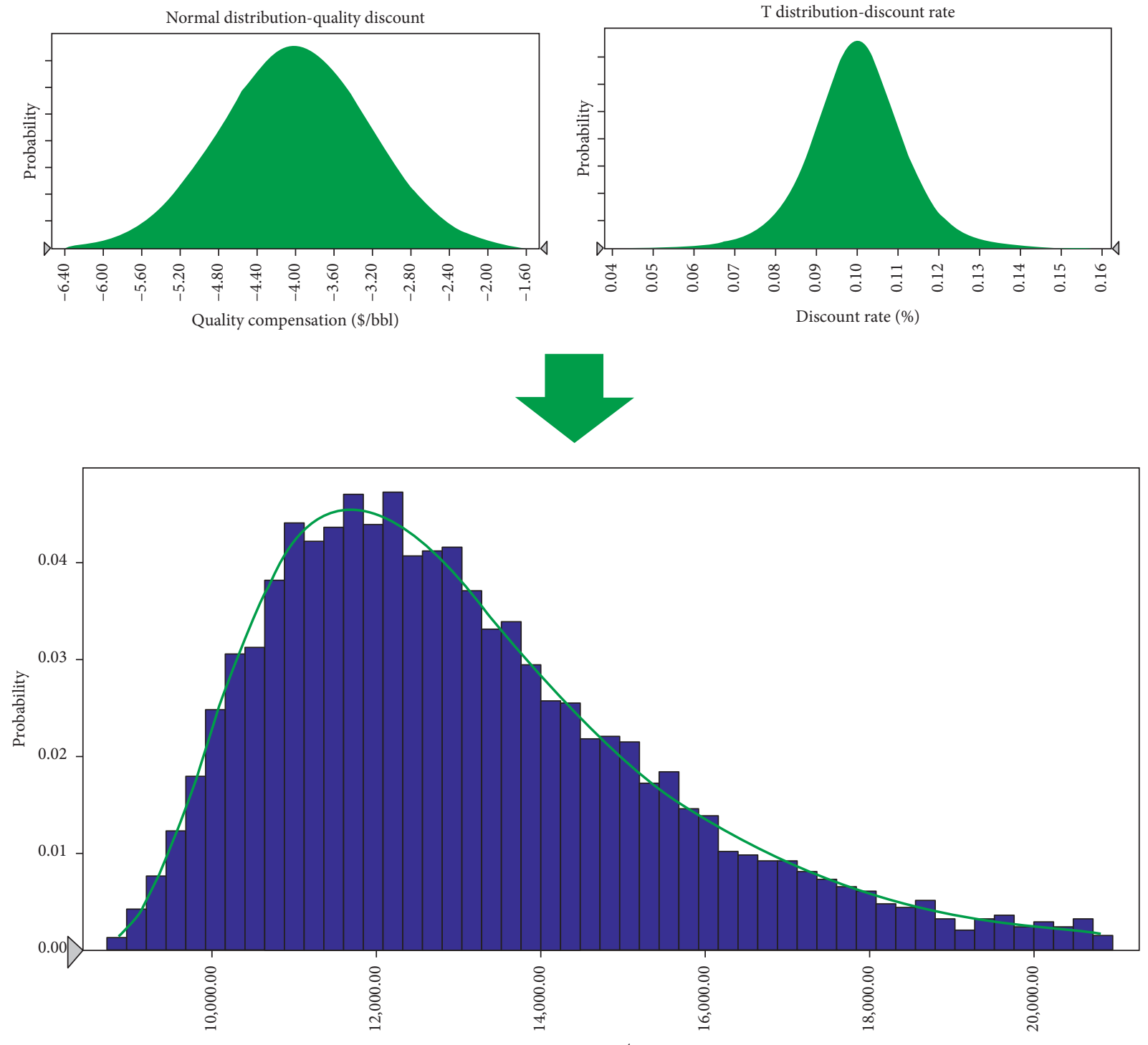

PV $\left(10^{4} \$\right)$

FIgURE 7: Probability distributions of the global oil price, quality compensation, discount rate, and the present value $V_{5}$ of future production earnings at the decision point "production." 

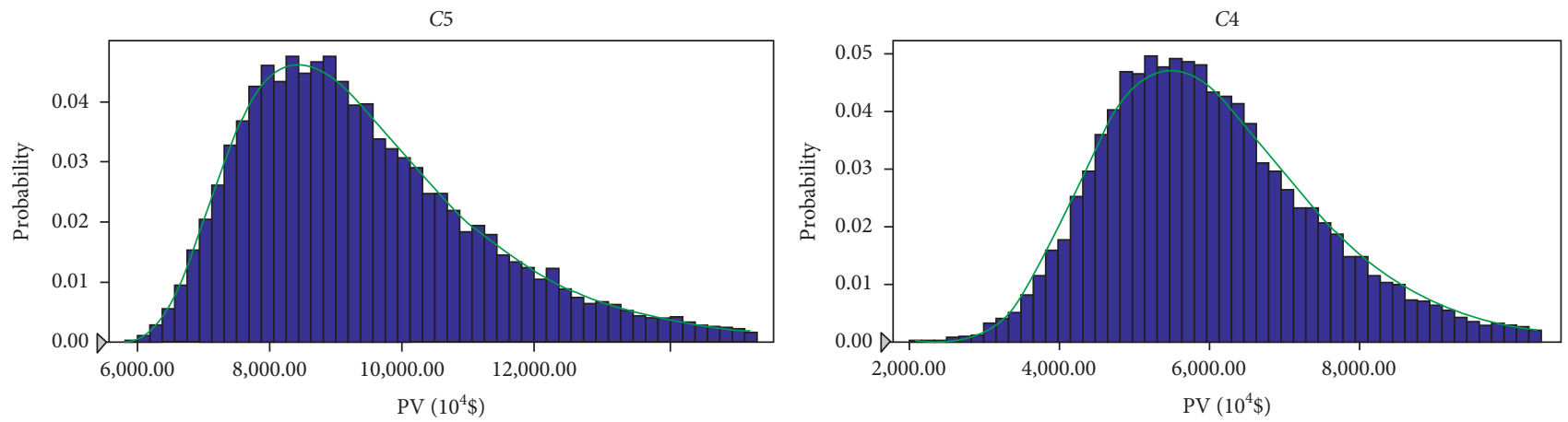

Figure 8: Probability distributions of $C_{4}$ and $C_{5}$.

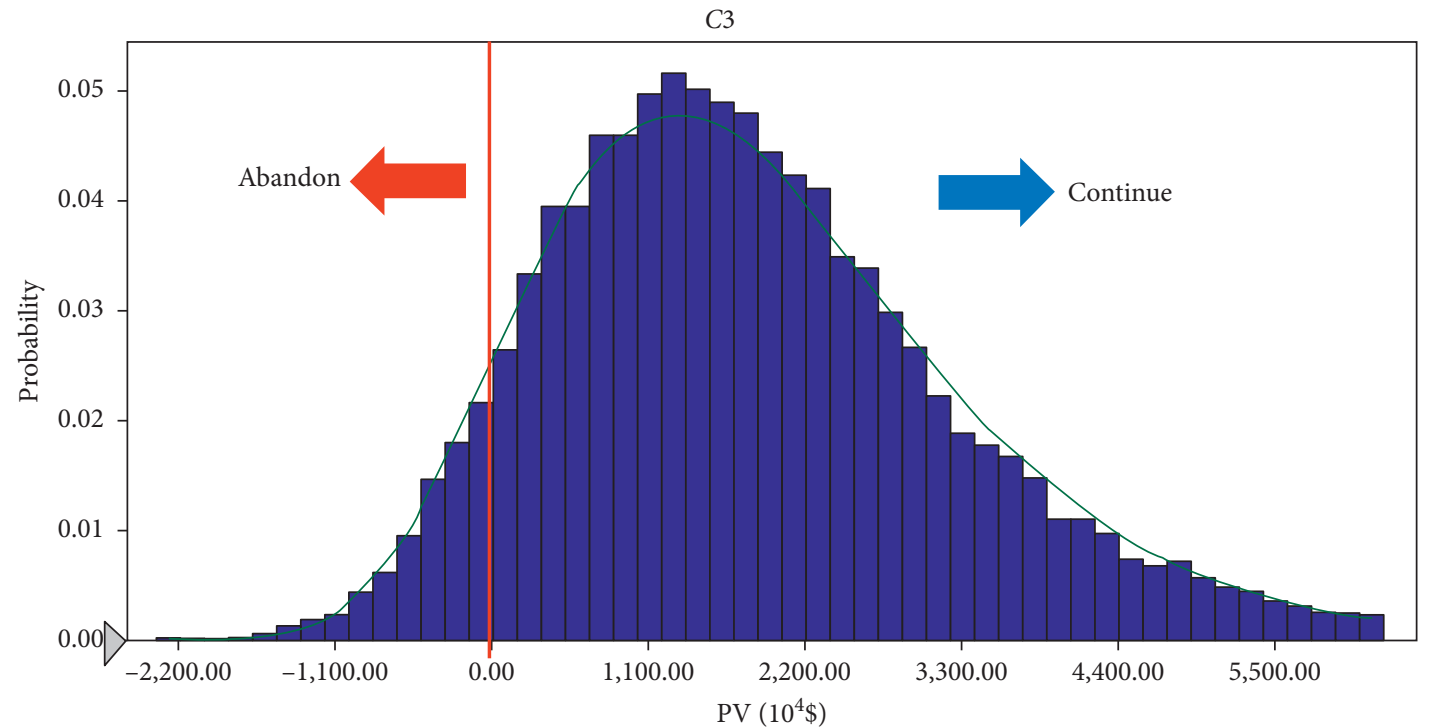

Figure 9: Probability distribution of the future value of extraction at the decision point "trap exploration."

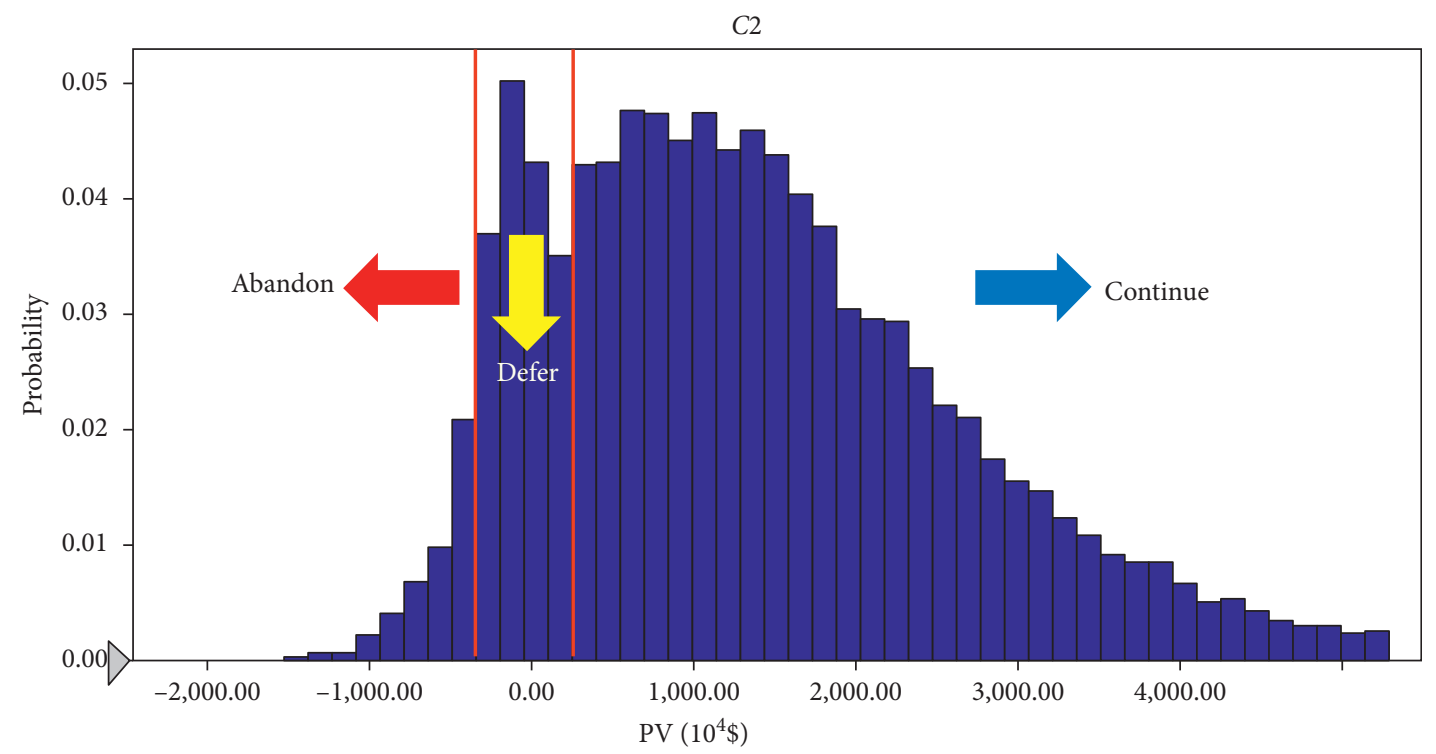

Figure 10: Probability distribution of $\mathrm{C}_{2}$. 


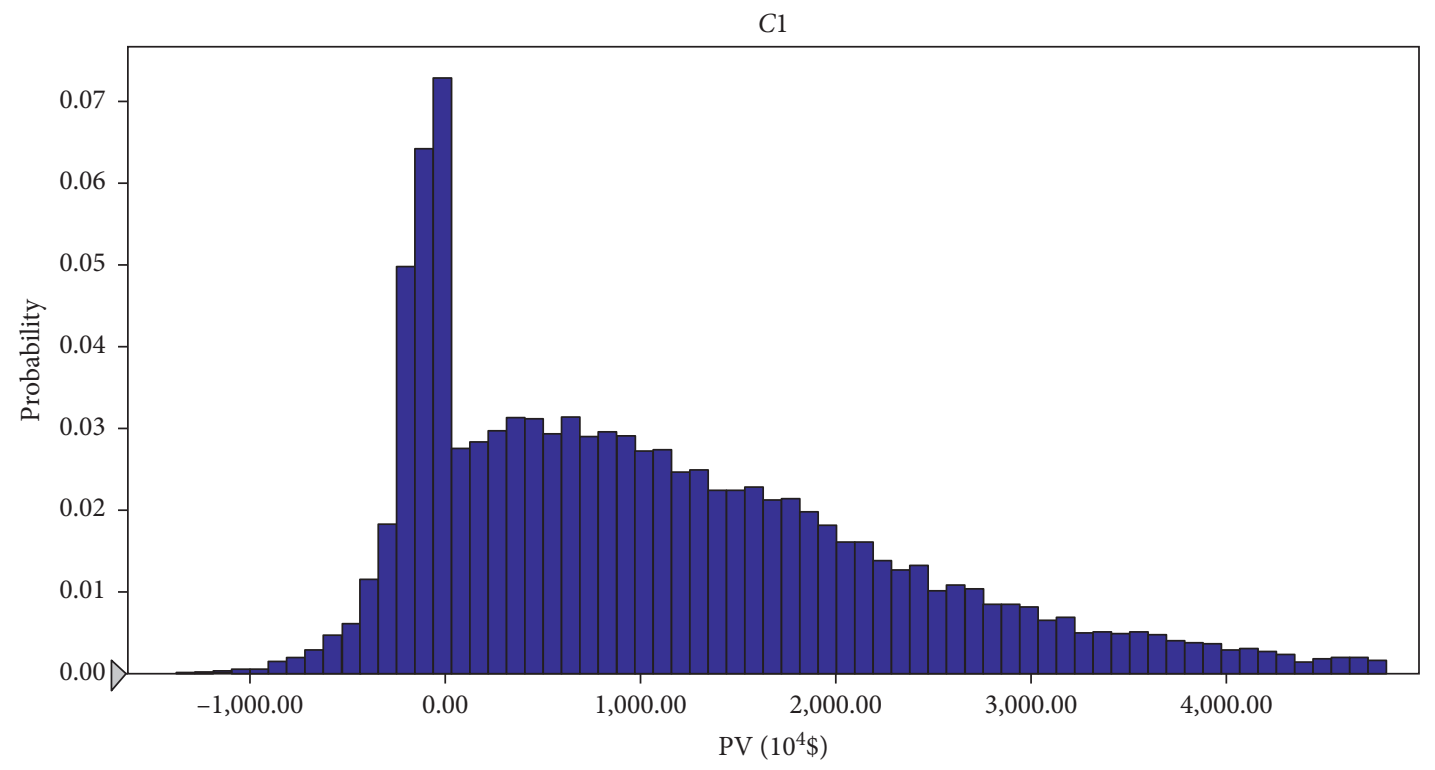

Figure 11: Probability distribution of $C_{1}$.

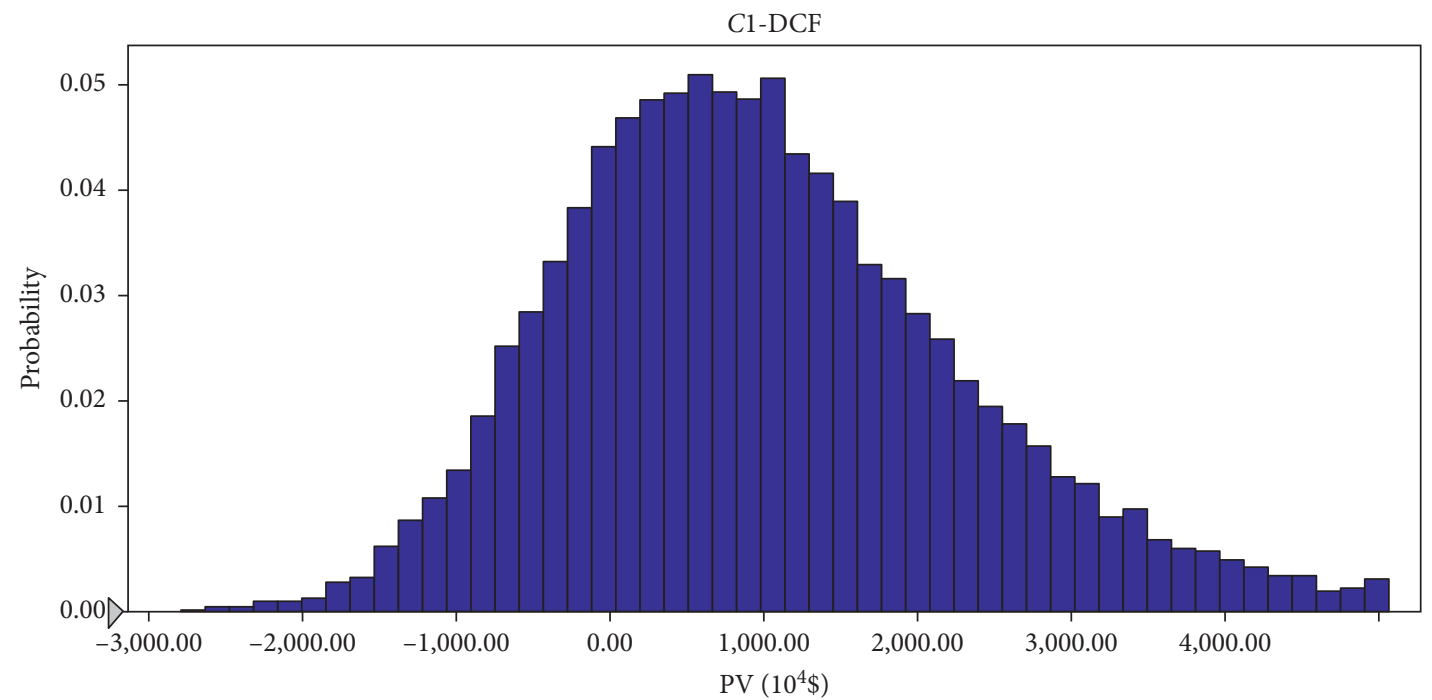

Figure 12: Probability distribution of $C_{1}$, without considering the decision rights.

TABLE 6: A comparison between oil and gas asset value at each decision point with and without the value of decision rights (million US dollars).

\begin{tabular}{lccccc}
\hline Decision point & $\mathrm{C}_{5}$ & $\mathrm{C}_{4}$ & $\mathrm{C}_{3}$ & $\mathrm{C}_{2}$ & $\mathrm{C}_{1}$ \\
\hline With options & 82.93 & 46.87 & 13.64 & 12.52 & 11.48 \\
Without options & 82.93 & 46.87 & 13.17 & 11.74 & 10.58 \\
Cumulative value of decision rights & 0 & 0 & 0.46 & 0.78 & 0.9 \\
\hline
\end{tabular}

\section{Conclusions}

The value of overseas oil and gas assets includes the cash flow value of future oil and gas development and the value of decision rights at each decision point. The distribution and transmission efficiency of uncertainty factors of assets will affect the value of decision rights. This paper holds that there are five major decision points and three major decision strategies in the oil and gas asset development. Combined with the discounted cash flow technique and the Trinomial Tree Option Pricing Model, a probability tree was constructed to replace the traditional decision tree, thereby 
obtaining an evaluation method that can be used to calculate the probability distribution of the value of decision rights at each decision point in inverse order. Taking into account the value of decision rights and avoiding the determination of volatility of oil and gas assets, this method can maximally utilize the original information about uncertainty factors and reflect the risks of oil and gas asset development to a certain extent. The details are as follows:

(1) Future decision rights of overseas oil and gas extraction are valuable, and the asset valuation should incorporate composite values of future cash flow and decision rights. How much the decision right should be valued is dependent on the probability distribution of assets affected by uncertainty factors. It is embodied as that deferring or abandoning strategies can be implemented in the case of high odds of future losses. However, it is not the case that higher uncertainty leads to higher values of decision rights, because the value of extraction probability distribution is under joint effects of the strategy space and future cash flow.

(2) The value of extraction presents varied volatility ratios at different time points. The value volatility is not only affected by oil prices, but also dependent on superposition of situations of each factor. According to the quantification of the impact of uncertainties on development value, the available information can be to the greatest extent exploited by using the probability distribution. The resultant calculation of value distribution can efficiently deal with the issue aroused by difficulties in determining volatility ratios of real option methods.

(3) The reality decides that oil and gas extraction, similar to the Bermuda option, is seen with infinite decision points, and thus the tree option pricing model is applicable. This paper replaces the decision-based tree model with the probability-based tree model to solve the problem that we are not able to plot and handle an $\mathrm{N}$-ary tree with infinite upward and downward points and precisely computes the probability distribution of the value of extraction at each decision point in a backward manner. The value probability distribution can not only represent how much the asset should be valued but also represent how high risks are, with respect to its disperse degree. By comparison, incorporation of decision-making alters the probability distribution of the value of extraction, which makes it more practical, and is conducive to asset valuation and investment decision-making.

Finally, an in-depth study on the distribution types of uncertainty factors of oil and gas assets needs to be carried out: If the types of uncertainty factors can be further divided and the distribution types of uncertainty factors can be proved more accurately, then the calculated value of oil and gas assets will be more accurate. In future research, the team will analyze and discuss each kind of uncertainty factors and propose a processing method to deal with possible noninevitable decision points, in order to build a more accurate and practical model.

\section{Data Availability}

The data used to support the findings of this study are included within the article.

\section{Conflicts of Interest}

The authors declare no conflicts of interest.

\section{Acknowledgments}

This work was funded by a National Science and Technology major project (2016ZX05042-002-004).

\section{Supplementary Materials}

The Excel sheet explains the calculation process of the case presented in Section 4.3. By using the Crystal Ball plugin of Excel, the uncertainty factor is simulated to calculate the value of each decision point. (Supplementary Materials)

\section{References}

[1] Q. Wang, S. Y. Li, and R. R. Li, "China's dependency on foreign oil will exceed $80 \%$ by 2030 : developing a novel NMGM-ARIMA to forecast China's foreign oil dependence from two dimensions," Energy, vol. 163, pp. 151-167, 2018.

[2] L. X. Mu, J. Pan, Z. Tian, Z. Ji, G. Hu, and S. Yuan, "The overseas hydrocaron resources strategy of Chinese oil-gas companies," Acta Petrolei Sinica, vol. 34, no. 5, pp. 1023-1030, 2013, in chinese.

[3] X. P. Hu, "Carrying out the globe resource strategy:"going abroad" to develope overseas resources," Geology and Prospecting, vol. 39, pp. 74-76, 2003, in chinese.

[4] L. Mu, Z. Fan, and A. Xu, "Development characteristics, models and strategies for overseas oil and gas fields," $P e$ troleum Exploration And Development, vol. 45, no. 4, pp. 735-744, 2018.

[5] G. F. Fa, R. E. Yuan, J. Lan, Q. Zou, and Z. Y. Li, "Net reserves evaluation and sensitivity analysis of shale gas project under royalty \& tax system in British Columbia, Canada," Third International Conference On Energy Engineering And Environmental Protection, vol. 227, 2019.

[6] Y. Song, X. H. Qiu, H. J. Li, and L. X. Sui, "Flexibility value in M\&A decision making for overseas oil and gas assets," in Proceedings of the International Conference On Energy And Environment Engineering (ICEEE 2015), IEEE, Nanjing, China, pp. 565-571, April 2015.

[7] W. Li, D. Luo, and J. Yuan, "A new approach for the comprehensive grading of petroleum reserves in China: two natural gas examples," Energy, vol. 118, pp. 914-926, 2017.

[8] R. Guo, D. Luo, X. Zhao, and J. Wang, "Integrated evaluation method-based technical and economic factors for international oil exploration projects," Sustainability, vol. 8, no. 2, 2016.

[9] R. Weijermars, "Economic appraisal of shale gas plays in Continental Europe," Applied Energy, vol. 106, pp. 100-115, 2013. 
[10] H. Liu, "Study on flaws and improvement of discounted cash flow theory in mergers and acquisitions," in Proceedings of the 2008 4th IEEE International Conference on Management of Innovation and Technology, pp. 1337-1341, Bangkok, Thailand, September 2008.

[11] D. G. Carmichael, "A cash flow view of real options," The Engineering Economist, vol. 61, no. 4, pp. 265-288, 2016.

[12] L. M. Abadie and J. M. Chamorro, "Valuation of real options in crude oil production," Energies, vol. 10, no. 8, 2017.

[13] B.-J. Tang, H.-L. Zhou, H. Chen, K. Wang, and H. Cao, "Investment opportunity in China's overseas oil project: an empirical analysis based on real option approach," Energy Policy, vol. 105, pp. 17-26, 2017.

[14] J.-Y. Huang, Y.-F. Cao, H.-L. Zhou, H. Cao, B.-J. Tang, and N. Wang, "Optimal investment timing and scale choice of overseas oil projects: a real option approach," Energies, vol. 11, no. 11, 2018.

[15] M. N. Fonseca, E. d. O. Pamplona, V. E. d. M. Valerio, G. Aquila, L. C. S. Rocha, and P. Rotela Junior, "Oil price volatility: a real option valuation approach in an African oil field," Journal of Petroleum Science and Engineering, vol. 150, pp. 297-304, 2017.

[16] D. Lund and R. Nymoen, "Comparative statics for real options on oil: what stylized facts?" The Engineering Economist, vol. 63, no. 1, pp. 54-65, 2017.

[17] L. Zhan, C. M. Yang, and S. Hu, Risk Assessment and Prevention in Oil-Gas Exploration Industry: The Tarim Basin as the Case, Universe Academic Press Toronto, Toronto, Canada, 2008.

[18] A. Ghandi and C. Lawell, "On the rate of return and risk factors to international oil companies in Iran's buy-back service contracts," Energy Policy, vol. 103, pp. 16-29, 2017.

[19] A. Z. Yin, "Study on economic evaluation index system of oilgas exploration project," in Advanced Research on Information Science, Automation and Material System, H. Zhang, G. Shen, and D. Jin, Eds., pp. 1693-1696, Trans Tech Publications Ltd, Stafa-Zurich, Switzerland, 2011.

[20] H. Xie, Q. Guo, F. Li et al., "Prediction of petroleum exploration risk and subterranean spatial distribution of hydrocarbon accumulations," Petroleum Science, vol. 8, no. 1, pp. 17-23, 2011.

[21] C. Wegener, T. Basse, F. Kunze, and H.-J. von Mettenheim, "Oil prices and sovereign credit risk of oil producing countries: an empirical investigation," Quantitative Finance, vol. 16, no. 12, pp. 1961-1968, 2016.

[22] Y. Yang, J. Li, X. Sun, and J. Chen, "Measuring external oil supply risk: a modified diversification index with country risk and potential oil exports," Energy, vol. 68, pp. 930-938, 2014.

[23] G. H. Pei and X. L. Huang, Application of NPV Method in Oilfield Well Pattern Design, Orient Acad Forum, Marrickville, Australia, 2008.

[24] D. G. Quirk and R. Ruthrauff, "Analysis of reserves discovered in petroleum exploration," Journal of Petroleum Geology, vol. 29, no. 2, pp. 125-146, 2006.

[25] E. D. Attanasi and R. R. Charpentier, "Comparison of two probability distributions used to model sizes of undiscovered oil and gas accumulations: does the tail wag the assessment?" Mathematical Geology, vol. 34, no. 6, pp. 767-777, 2002.

[26] Y. Q. Zhou and L. Yan, "Comparing two models for evaluating an oilfield development project: mean-reversion with Jumps, geometric brownian motion," Advanced Materials Research, vol. 616-618, pp. 1568-1572, 2013.
[27] X. Zhu and Z. Guo, "Simulation study on forecasting method of oil price forecasting," Computer Simulation, vol. 28, no. 6, pp. 361-364, 2011.

[28] Y. Zhang, J. He, and T. Yin, "Research on petroleum price prediction based on SVM," Computer Simulation, vol. 29, no. 3, p. 375, 2012.

[29] C. Y. Lee, "Long-term crude oil price forecast using the bayesian model," POSRI Business and Economic Review, vol. 11, no. 2, pp. 58-86, 2011.

[30] C. Baumeister and L. Kilian, "Forecasting the real price of oil in a changing world: a forecast combination approach," Journal of Business \& Economic Statistics, vol. 33, no. 3, pp. 338-351, 2015. 